\title{
Wenn Mythologie politisch wird: War Aeneas der Stammvater Roms oder nicht?
}

(vorgetragen in der Plenarsitzung am 29. Oktober 2010)

\author{
HeinZ-GÜNTher Nesselrath
}

Im Jahre 27 v. Chr. wird der Sieger des letzten der großen Bürgerkriege, die die römische Republik zerstörten, vom römischen Senat zum „Augustus" erklärt - ein Titel, den fortan alle römischen Kaiser tragen und der bei seinem ersten Träger sogar zum persönlichen Namen wird. Etwa zur gleichen Zeit entstehen in Rom drei literarische Werke, die den Mythos der römischen Stadt- und Staatsgründung in eine Form bringen, die fortan für alle Zeit - jedenfalls bis in unsere Gegenwart - kanonisch sein wird: Das 1. Buch der Rhomä̈kai Archaiotētes - einer römischen Frühgeschichte in 20 Büchern - des griechischen Redelehrers und Literaturkritikers Dionysios von Halikarnass ist ganz der Ursprungssage bis zur Gründung Roms gewidmet und arbeitet auch sehr ausführlich die Verbindungen zwischen dem mythischen Troja und Italien heraus; die ersten sieben Kapitel des ersten Buchs der umfangreichen Geschichte Roms - unter dem Titel $A b$ urbe condita - des römischen Geschichtsschreibers Titus Livius stellen ebenfalls die Ursprungsgeschichte bis zur Stadtgründung dar; die wichtigste und am meisten maßgeblich gewordene Fassung des Übergangs von Troja nach Rom bietet jedoch Vergils Aeneis, die ebenfalls in dieser Zeit (im wesentlichen in den 20er Jahren v. Chr.) entsteht.

Im Mittelpunkt der Aeneis steht der trojanische Held Aineias/Aeneas, der bei Vergil zu einem „Brückenkopf“ zwischen Ost und West, zwischen dem Mythos des Trojanischen Krieges und den Anfängen Roms wird. Aineias ist der Spross einer Nebenlinie des trojanischen Königshauses und auf trojanischer Seite der bedeutendste Held, der den Trojanischen Krieg überlebt: Bereits in den im 7. und im 6. Jh. v. Chr. entstandenen Werken des sogenannten epischen Kyklos - einer Reihe von größeren griechischen Gedichten, die Ursprung, Verlauf und Folgen des Trojanischen Krieges darstellen wird in verschiedenen Versionen erzählt, wie Aineias kurz vor der Eroberung Trojas die Stadt verlässt; schon im 6. Jh. gibt es auch Vasendarstellungen, die Aineias zeigen, wie er auf dieser Flucht seinen Vater Anchises auf den Schultern trägt und seinen kleinen Sohn Askanios an der Hand führt. 
Schon im späteren 5. Jh. v. Chr. gab es dann auch Darstellungen, in denen Aineias offenbar bereits bis nach Italien gelangte, etwa bei den Geschichtsschreibern Hellanikos von Lesbos (FGrHist 4 F 84) und Damastes von Sigeion (FGrHist 5 F 3). Damit hätte Aineias schon fast vierhundert Jahre vor Dionys, Livius und Vergil den großen Schritt nach Westen getan.

Nun gibt es jedoch vor allem in der sehr quellen- und zitatreichen Darstellung des Dionys bemerkenswerte Hinweise darauf, dass diese schöne Geschichte, die den Römern direkten Anschluss an ein besonders heroisches Kapitel des griechischen Mythos bietet - Aineias überlebt den Trojanischen Krieg, geht nach Italien und wird hier zum Stammvater Roms bei weitem nicht die einzige Version ist, die seit dem 5. Jh. im Umlauf war, sondern dass es durchaus auch ganz andere gab, in denen Aineias keine so großen Wanderungen vollzieht und in denen er auch nicht immer eine rein positive Figur ist: So soll Aineias laut Menekrates von Xanthos (FGrHist 769 F 3) die Stadt Troja den Griechen ausgeliefert und zum Dank dafür freien Abzug erhalten haben; war der strahlende Held also nur ein schnöder Verräter?

Andere Autoren lassen ihn zwar aus Troja weg-, aber nicht bis nach Italien kommen: Laut Ar(i)aithos (FGrHist 316 F 1), dem Verfasser einer Lokalgeschichte Arkadiens kam Aineias nur bis nach Arkadien und gründete dort die Stadt Kapyai (benannt nach seinem Großvater Kapys). Bei noch weiteren Autoren gelangte Aineias sogar nur nach Thrakien und starb dort, so bei Hegesippos von Mekyberna (FGrHist 391 F 5) und bei Hegesianax von Alexandria Troas (FGrHist $45 \mathrm{~F}$ 7); freilich lässt Hegesianax dann immerhin vier Söhne des Aineias nach Italien gelangen, von denen Rhomos Rom gründet. Um die Mitte des 2. Jh.s v. Chr. vertrat der ebenfalls aus der Troas stammende antiquarische Gelehrte und Schriftsteller Demetrios von Skepsis sogar die These (die sich bis ins 20. Buch der homerischen Ilias zurückverfolgen lässt), dass Aineias überhaupt nie nach Westen gegangen, sondern in der Troas geblieben sei und seinen Nachkommen ein lokales Fürstentum vererbt habe. Noch mitten in der augusteischen Zeit als Aineias längst, wie eingangs gesehen, zum kanonischen Ur-Vater Roms geworden ist - wird eine solche Ansicht von dem bedeutenden griechischen Geographen Strabon vertreten $(13,1,53)$, der uns einerseits die gerade skizzierte Ansicht des Demetrios von Skepsis referiert und sich andererseits selbst auf Ilias Buch 20 beruft, wo von einer künftigen Herrschaft der Aineias-Nachkommen eben in der Troas, nicht aber im Westen des Mittelmeeres die Rede ist.

Ferner nennt eine Reihe von griechischen Autoren nicht Aineias, sondern andere Personen als Stammväter Roms: Der Philosoph Aristoteles (fr. 609 
Rose) lässt Rom durch von Troja heimkehrende Griechen gründen, die ein Sturm nach Italien verschlägt. Der Schriftsteller Xenagoras (FGrHist 240 F 29) erklärt keinen geringeren als den berühmten Odysseus zum Stammvater Roms: Dieser habe mit Kirke drei Söhne namens Rhomos, Anteias und Ardeias gezeugt, die die Städte Rom, Antium und Ardea gegründet hätten. Bei Kallias von Syrakus (FGrHist 564 F 5a) gelangt eine Trojanerin namens Rhome mit anderen Trojanern nach Italien, heiratet dort den König Latinos und hat mit ihm die Söhne Rhomos, Rhomylos und Telegonos, die eine Stadt gründen und nach ihrer Mutter benennen. Andere (namentlich nicht bekannte) Autoren (zitiert bei Plut. Rom. 1,1) nennen als Gründer die Pelasger, ein Ur-Volk, das griechische Autoren gern als Lückenbüßer überall dort einführen, wo sie nur spekulieren können. Noch andere (ebenfalls namentlich unbekannte, zitiert bei Dionys Ant. I 72,6) wollen Rom sogar nur einen rein italischen Ursprung von einem Gründer Rhomos (einem Sohn des Italos und der Latinos-Tochter Leukaria) zuweisen.

Möglicherweise handelt es sich bei all diesen Varianten nicht nur um reine gelehrte (oder pseudo-gelehrte) Glasperlenspiele: Es wurde bereits angedeutet, dass die Zurückführung der Ursprünge Roms auf den trojanischen Helden Aineias für die expandierende Macht Rom, die gerade in der Kulturwelt der griechischen Staaten um Ansehen und Respektabilität bemüht war, ein wichtiges Mittel zur Erlangung dieser Respektabilität sein konnte: Wer sich auf einen Aineias als Stammvater berufen kann, der schon bei dem großen Dichter Homer hohes Ansehen genießt, der braucht sich auch gegenüber noch so snobistisch auf ihre eigenen Traditionen pochenden Griechen nicht zu verstecken; und so haben die römischen Geschichtsschreiber seit Fabius Pictor und die römischen Dichter seit Naevius und Ennius immer wieder Aineias an den Anfang der römischen Geschichte gestellt.

Diese Ansprüche sind freilich bei den Griechen nicht immer auf Gegenliebe gestoßen, besonders zu Zeiten, da sie die volle Härte römischer Expansions- und Eroberungspolitik zu spüren bekamen: Im Zweiten Punischen Krieg wagte es die unteritalische Stadt Tarent, von den Römern abzufallen, und musste dies mit einer blutigen Eroberung bezahlen. Das griechische Mutterland musste solche Erfahrungen bald ebenfalls machen; sie erreichten einen ersten traurigen Höhepunkt mit der Zerstörung der reichen Stadt Korinth (146 v. Chr.); damals wurde Muttergriechenland römische Provinz und verlor seine zuvor noch wenigstens nominell vorhandene politische Freiheit. Zu dieser Zeit hatten die römischen Legionen bereits weit ins östliche Mittelmeer ausgegriffen und die ehemals mächtigen hellenistischen Staaten entweder schon vernichtet (so Makedonien) oder zu 
mehr oder weniger subalternen Befehlsempfängern degradiert (so das Reich der Seleukiden und das der Polemäer). In von Griechen bewohnten Gebieten, die unter direkter römischer Herrschaft standen (seit 133 v. Chr. gehörte auch das westliche Kleinasien dazu), führte die römische Provinzverwaltung zu immer mehr Unzufriedenheit: Statt ihren Untertanen eine anständige Verwaltung zu bieten, plünderte sie sie vielmehr regelrecht aus oder gab sie vom Staat geförderten Ausplünderern preis. Die Unzufriedenheit entlud sich schließlich in blutigen Racheakten gegen Römer, als König Mithridates VI. von Pontos seit 88 v. Chr. als Griechenbefreier auftrat; erst mehr als zwanzig Jahre später konnte er von den Römern endgültig überwunden werden. Bald danach trat dann die Epoche der innerrömischen Bürgerkriege in ihre gewalttätigste Phase und zog gerade die griechische Mittelmerwelt in große Mitleidenschaft: Sowohl der Kampf zwischen Caesar und Pompeius in den Jahren 49-45 als auch der Kampf des neuen Triumvirats mit den Caesarmördern 44-42 und schließlich der letzte Waffengang zwischen Marcus Antonius und dem späteren Augustus 32-30 fanden vor allem im griechischen Osten statt.

Vor diesem historischen Hintergrund sind starke (und auch literarisch geäußerte) griechische Ressentiments gegen römische Unterdrücker nicht verwunderlich. Zu einem großen Teil äußerten sich diese Ressentiments dabei in der These, dass die Römer nichts weiter als unedle Emporkömmlinge und Nachfahren von Vagabunden und Räubern seien, die sich kulturell in keiner Weise mit den Griechen messen könnten. Diese These lässt der Historiker Sallust den König Mithridates einmal in voller Schärfe formulieren (Hist. 5), und Dionys von Halikarnass nennt sie in der Einleitung seiner römischen Frühgeschichte als Motiv, gegen das vor allem er anschreiben möchte.

In diesem Zusammenhang nun könnten die oben zitierten Varianten zur römischen Gründungsgeschichte in einem neuen Licht erscheinen und vielleicht auch verschiedene Strategien zeigen, um den Anspruch der Römer auf eine respektable Vorgeschichte zu konterkarieren: Eine Möglichkeit war, die Stammvaterschaft des Aineias zwar nicht zu leugnen, sie aber dadurch zu entwerten, dass man diesen Stammvater zu einem Verräter an seiner eigenen Vaterstadt macht (so Menekrates von Xanthos); eine andere lässt den Nimbus des Aineias zwar bestehen, nimmt aber den Römern die Möglichkeit, ihn zu ihren Gunsten zu verwenden, dadurch weg, dass man Aineias erst gar nicht nach Italien kommen, sondern in Kleinasien bleiben oder zumindest lange vor einer Ankunft in Italien (in Thrakien oder mitten in der griechischen Peloponnes) sterben lässt, womit er nicht mehr zum Ur-Vater Roms werden kann. Eine ähnliche Tendenz könnte man bei 
Autoren vermuten, die explizit andere Personen als Aineias zu Gründern oder Stammvätern Roms machen (so Aristoteles, Xenagoras, Kallias von Syrakus und andere namentlich nicht bekannte).

Es bleibt hier freilich die Unsicherheit, dass es oft nur vage Vermutungen darüber gibt, wann die betreffenden Autoren gelebt haben: Menekrates von Xanthos soll im 4. Jh. v. Chr. geschrieben haben, Hegesippos von Mekyberna und Kephalon von Gergitha werden von Dionys von Halikarnass als „Männer alter Zeit" bezeichnet; im Fall des Hegesippos nimmt man eine Datierung um 300 v. Chr. an, bei Kephalon von Gergitha handelt es sich jedoch um ein Pseudonym des Hegesianax von Alexandria in der Troas (FGrHist $45 \mathrm{~F} 1$ ), von dem wir etwas mehr wissen: Er gehört ins späte 3. und frühere 2. Jh. v. Chr. und war ein "Philos“ (d. h. ein Vertrauter) des Seleukidenkönigs Antiochos III. (vgl. Demetr. Sceps. fr. 7 Gaede). Wenn nun aber Dionys diesen Mann, der nur etwa 150 Jahre früher lebte als er selbst, als „Mann alter Zeit" bezeichnen konnte, dann muss man vielleicht auch den ebenso bezeichneten Hegesippos nicht viel früher ansetzen.

Bei den übrigen erwähnten Autoren - mit Ausnahme des Aristoteles, der bekanntlich zwischen 384 und 322 v. Chr. gelebt hat - bleiben die Datierungen ähnlich vage: $\operatorname{Ar}(\mathrm{i})$ aithos wird im 4. Jh. v. Chr. vermutet, Xenagoras im mittleren 3. Jh. v. Chr., Kallias von Syrakus lässt sich als Hofhistoriker des Alleinherrschers Agathokles von Syrakus (etwa 360 bis 289 v. Chr.) ins späte 4. bzw. frühe 3. Jh. v. Chr. datieren.

Einige der gerade genannten Autoren sind, wenn sie noch ins 4. oder frühere 3. Jh. v. Chr. zurückgehen, wohl tatsächlich zu früh, als dass man ihnen eine romkritische oder gar romfeindliche Tendenz zuschreiben könnte; denn erst seit den letzten Jahrzehnten des 3. Jh.s wurde die Expansion Roms auch in Muttergriechenland und im östlichen Mittelmeerraum als Bedrohung wahrgenommen und entwickelten sich die oben skizzierten Antipathien. Bei Hegesianax von Alexandria Troas wurde früher gelegentlich angenommen, dass auch er von antirömischen Ressentiments beeinflusst gewesen sein könnte: Hegesianax' Monarch, der Seleukide Antiochos III., geriet seit 196 v. Chr. in zunehmenden Konflikt mit Rom (im Jahr 195 gewährte er sogar dem römischen Erbfeind Hannibal Asyl!); dieser Konflikt wurde $192 \mathrm{zu}$ einem regelrechten Krieg, in dem Antiochos bald den Kürzeren zog und seine Ambitionen als Vorkämpfer der Griechen endgültig begraben musste. Nun lässt aber Hegesianax zumindest Aineias' Sohn Rom gründen, womit der mythische Anspruch auf den großen Vorfahr natürlich erhalten bleibt. Andere aber haben nun gerade in den mittleren Jahrzehnten des 2. Jh.s - als der römische Militärstiefel bereits sehr dröhnend in der östlichen Mittelmeerwelt auftrat - der römischen Berufung auf Aineias 
offensichtlich die Stirn geboten, so der erwähnte Demetrios von Skepsis, und von hier lassen sich Linien bis ins 1 . Jh. v. Chr. ziehen, bis hin zu Strabon, der sich allen römischen Ansprüchen gegenüber unbeirrt auf seinen Homer beruft, demzufolge die Aineiaden in der Troas geblieben seien. Spielte dabei eine Rolle, dass Strabons Vater eine angesehene Persönlichkeit gerade in der Entourage des großen Römerfeindes Mithridates war?

Nun lassen sich in dieser Zeit aber auch (vielleicht von den Römern geförderte) Versuche feststellen, solchen Stimmen entgegenzutreten, und diese Versuche dürften dazu beigetragen haben, dass sich die Version von Aineias als Vor-Vater Roms schließlich doch durchsetzen konnte. So korrigierte der arkadische Dichter Agathyllos (wohl 2. oder 1. Jh. v. Chr.) wohl ganz bewusst Versionen, in denen Aineias nur bis Arkadien kam, und zog in seinen bei Dionys (Ant. 1,49,2) zitierten Versen die Linie weiter: „Er kam nach Arkadien und setzte in Nesos zwei Söhne ein [. . .]; er selbst aber eilte (weiter) ins hesperische Land und zeugte (dort) den Sohn Romylos." Es gab sogar Bemühungen (zitiert bei Strabon 13,1,53 a. E), das Haupthindernis für eine Westfahrt des Aineias, eben die berühmte Prophezeiung des Gottes Poseidon in der Ilias, die eine Herrschaft von Aineiaden in der Troas (und nur dort) voraussagte, textlich so zu ändern, dass sie nunmehr auf die römische Weltherrschaft verwies. Dazu musste man den Vers (Il. 20,307) "Jetzt wird die Kraft des Aineias über die Troer herrschen" nur minimal ändern: „Jetzt wird das Geschlecht des Aineias über alle herrschen." Vergil scheint diese neue Version im 3. Buch der Aeneis (V. 97f.) geradezu zitiert zu haben.

So zeichnet sich noch in Umrissen das Bild eines publizistischen Kampfes ab, in dem die Römer mit ihren Ansprüchen auf die Stammvaterschaft des Aineias sich bemerkenswerten Herausforderungen gegenüber sahen, diese aber letztlich zurückweisen und verdrängen konnten. 